Surg Endosc (2002) 16: 1120

DOI: $10.1007 / \mathrm{s} 00464-001-8352-\mathrm{y}$

CC Springer-Verlag New York Inc. 2002

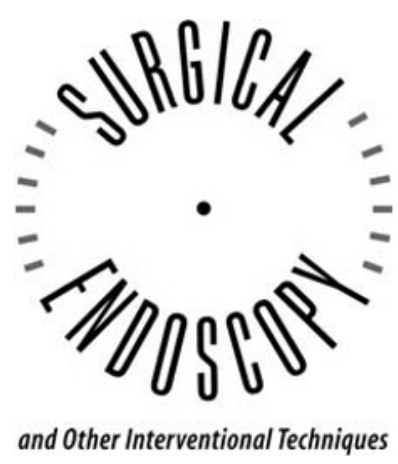

\title{
Guidelines for laparoscopic and open surgical treatment of morbid obesity
}

A number of members of both the American Society for Bariatric Surgery (ASBS) and the Society of American Gastrointestinal Endoscopic Surgeons (SAGES) collaborated on the important guidelines for laparoscopic and open bariatric surgery. They were approved by both the ASBS and SAGES and published in Obesity Surgery in August 2000 [2]. Under the title, we set the following acknowledgment: "Document adopted by both the American Society for Bariatric Surgery and the Society of American Gastrointestinal Endoscopic Surgeons, June 2000."

The guidelines were also published in the October 2001 issue of Surgical Endoscopy [1], but there is no mention of the joint involvement of the ASBS. The wording and references are identical to the final revised document in Obesity Surgery [2]. Acknowledgement of the participation of the ASBS would provide further validity for these guidelines. The ASBS, founded in 1983, includes 750 surgeons and allied health practitioners devoted to bariatric surgery.

\section{Commentary by Sallie Matthews, Executive Director, SAGES}

$S A G E S$ regrets the omission of reference to the American Society for Bariatric Surgery (ASBS) in the original printing of these guidelines. The guidelines are currently under revision and will be published jointly, if the revisions meet with ASBS approved.

\section{References}

1. Anonymous (2001) Guidelines for laparoscopic and conventional surgical treatment of morbid obesity. Surg Endosc 15: 12511252

2. Anonymous (2000) Guidelines for laparoscopic and open surgical treatment of morbid obesity. Obes Surg 10: 378-379

\section{K. B. Jones, Jr.}

American Society for Bariatic Surgery

1801 Fairfield, Suite 408

Shreveport, LA 71101, USA

\section{Deitel}

Obesity Surgery

5863 Leslie Street, Box 1002

Toronto, ON M2H 1J8, Canada

Online publication: 3 May 2002 